\title{
Enterotoxins from Clostridium difficile; diarrhoeogenic potency and morphological effects in the rat intestine
}

\author{
J Torres, E Jennische, S Lange, I Lönnroth
}

\begin{abstract}
The action of toxins $A, B$, and $C$ from Clostridium difficile was studied in the small intestine and colon of rats. All three caused fluid accumulation in the small intestine, maximal secretion being induced by $1 \mu \mathrm{g}$ of toxin $A$, $20 \mu \mathrm{g}$ of B, and $15 \mu \mathrm{g}$ of C. Both toxins $A$ and $C$ caused shedding of epithelial cells from the villi without visible damage to crypt cells; toxin A caused further extensive necrosis and bleeding. Toxin B caused secretion without visible damage to the epithelial cells, though this activity was unstable and decreased significantly after one week of storage. In the colon, toxin A caused secretion and shedding of surface epithelial cells without damage to crypt cells, toxin $\mathbf{C}$ caused only a weak secretion, and toxin $B$ had no effect at all. In terms of immunohistochemistry, it was found that toxin $A$ bound to the enterocytes at the tips of the villi but not to goblet and crypt cells. The complex expression or interaction of the toxins produced by $\mathrm{Cl}$ difficile may explain the broad spectrum of disease (diarrhoea, colitis, and pseudomembranous colitis) associated with this micro-organism.
\end{abstract}

Clostridium difficile is recognised as the primary cause of antibiotic associated pseudomembranous colitis ${ }^{1}$ but the extent to which it is responsible for antibiotic associated colitis and diarrhoea is unclear. ${ }^{23}$ The secreted toxins seem to be responsible for most clinical symptoms since the bacteria colonise the gut without being invasive. ${ }^{45}$ The toxins are all proteins with molecular weights above 100000 , and have been characterised chemically and biologically. Toxin A causes fluid accumulation and mucosal damage in the small intestine in hamsters and rabbits $^{67}$ but less tissue damage in the rabbit colon. ${ }^{89}$ It is possible that an initial cytophatic effect of toxin A on the intestinal mucosa is followed by an inflammatory response, endogenous mediators released by the inflammatory response cause necrosis followed by bleeding and extravasation from the intestinal wall to the lumen. ${ }^{79}$ No detailed histological studies have been done, however, to evaluate this hypothesis. Toxin B had no effect when tested in the rabbit intestine, ${ }^{7-9}$ although it is a potent cytotoxin for cells cultured in vitro. ${ }^{10}$

We recently isolated and characterised toxic peptides that are chemically and antigenically different from toxins A and B, ${ }^{11}$ and are referred to here as fraction $C$. Other toxic activities produced by $\mathrm{Cl}$ difficile have been reported but their limited characterisation ${ }^{12} 13$ does not allow comparison with the toxins already described.

In this paper we report the fluid response induced by toxins $A$ and $B$ and by fraction $C$ in ligated loops of the rat small intestine and in the colon. The histological appearance of the intestine is also described, together with the binding pattern of toxin A to the intestinal epithelium. The differences in the actions of these toxins on the intestine may explain the diversity of intestinal disorders associated with $\mathrm{Cl}$ difficile.

\section{Methods}

ANIMALS

Male Sprague-Dawley rats (ALAB, Sollentuna, Sweden) weighing 230-300 $\mathrm{g}$ were used. The animals were starved overnight before the study but were provided with water ad libitum.

\section{PREPARATION OF TOXINS}

$\mathrm{Cl}$ difficile strain CCUG 19126 (VPI 10463, obtained from D M Lyerly/T D Wilkins, VPI Blacksburg, USA) was used. The toxins A, B, and $C$ were purified to homogeneity from the crude bacterial broth as described elsewhere. ${ }^{114}$ Briefly, toxin B was separated from toxin A and fraction $C$ by DEAE-Sephadex anion exchange chromatography, followed by Sephacryl S-400 filtration and high resolution anion exchange chromatography on a mono $Q$ column, using fast protein liquid chromatography equipment. Toxins $\mathrm{A}$ and $\mathrm{C}$ were precipitated by acid $\mathrm{pH}$ and separated on a mono $Q$ column. All toxin preparations used in experiments were homogeneous, as demonstrated by double immunodiffusion in gel and by polyacrylamide electrophoresis. ${ }^{14}$ The concentration of the pure toxins was measured with a protein assay kit using Coomassie brilliant blue as the reagent (Bio-Rad Laboratories, Richmond, CA, USA).

\section{TOXIN A ANTIBODIES}

Toxin A antiserum was prepared in rabbits, ${ }^{11}$ and the IgG fraction was purified as described by Steinbuch et al. ${ }^{\text {is }}$ Briefly, the contaminating serum proteins were removed by precipitation with caprylic acid and by DEAE-Sephadex chromatography, leaving the IgG fraction to be precipitated with ammonium sulphate. This IgG fraction was then dissolved in phosphate buffered saline (PBS) $\mathrm{pH} 7 \cdot 2$, and dialysed against the same buffer. Two hundred $\mathrm{ml}$ of this IgG solution was adsorbed with $200 \mu \mathrm{g}$ of toxin $\mathrm{A}$ for one hour at room temperature. 
RAT INTESTINAL LOOP TEST

Rat intestinal loops were used to study the action of toxins A, B, and C. ${ }^{16}$ Ether was used for anaesthesia during the three to seven minute long operation, after which the animal recovered. No analgesic was used after the operation, since there was no evidence of pain. The small intestine was approached via a midline incision. Ligated loops, about $10 \mathrm{~cm}$ in length, were prepared in the jejunum. For the kinetic studies, two loops per rat were made, between which a blank loop was prepared. For histological studies, one loop per rat was prepared. Each loop was injected with $1 \mathrm{ml}$ of toxin in $20 \mathrm{mM}$ triethanolamine, $0.2 \mathrm{M} \mathrm{NaCl}, \mathrm{pH} 7 \cdot 5$. Controls were injected with triethanolamine, $\mathrm{NaCl}$ alone.

Loops, 10 to $12 \mathrm{~cm}$ in length, were also prepared in the transverse colon after careful rinsing of the whole colon with approximately $20 \mathrm{ml}$ of phosphate buffered saline $\left(37^{\circ} \mathrm{C}\right)$. These loops were injected with $2 \mathrm{ml}$ of the various toxins or triethanolamine, $\mathrm{NaCl}$; and the fluid accumulation was measured after six hours.

The resulting fluid secretion in both the small intestine and colon was calculated from the weight to length ratio of the loop $(\mathrm{mg} / \mathrm{cm})$ by subtracting the mean ratio of triethanolamine, $\mathrm{NaCl}$ injected loops from that of the toxin injected loops. In the kinetic studies (Fig 1) two loops were prepared on the small intestine. The numbers in the Table and Figures $(\mathrm{mg} / \mathrm{cm})$ represent the mean values of all the loops. The reproducibility of the fluid response to the different toxins did not vary more than $10 \%$ between the rats.

\section{HISTOLOGICAL STUDIES}

Rats under ether anaesthesia were given transcardial perfusion with $40-60 \mathrm{ml}$ ice cold $4 \%$ paraformaldehyde in phosphate buffered saline. The middle portion of the small or large intestinal ligated loop used for toxin or triethanolamine, $\mathrm{NaCl}$ injection was then cut into pieces about $5 \mathrm{~mm}$ long which were immediately immersed in the same fixative. The sections were immersions fixed for three to 12 hours, and then prepared for sectioning and staining.

Figure 1: Time course of the secretory response of rat small intestinal loops to $5 \mu \mathrm{g}$ of toxin A. Each data point represents the mean of values from five ligated loops and vertical bars the SEM.

\section{PLASTIC SECTIONS}

Small pieces of the intestinal loops were embedded in methacrylate plastic (Historesin R)

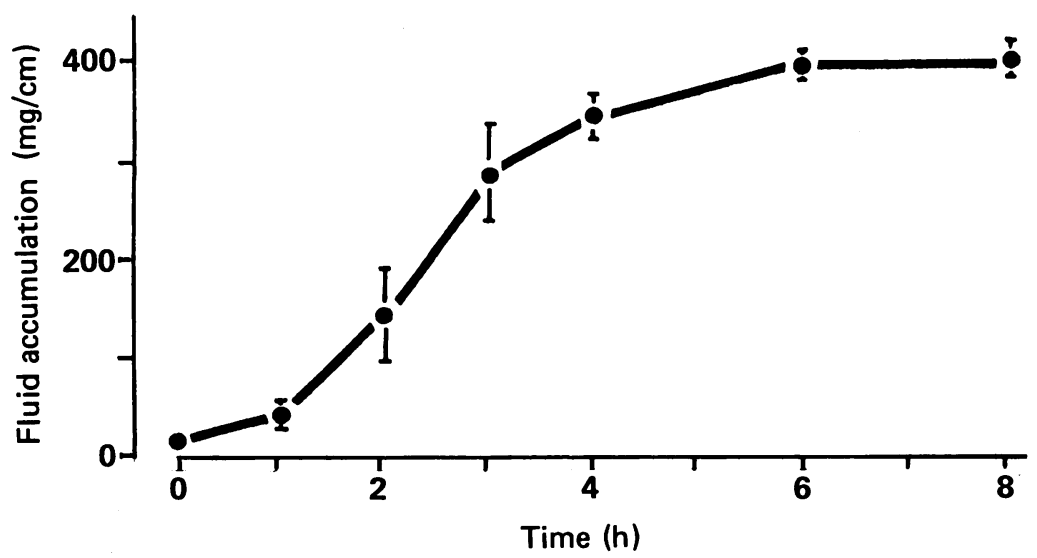

and $1 \mu \mathrm{m}$ thick sections were prepared using a Historaye microtome (LKB). Using standard procedures, the sections were either stained with basic fuchsin/methylene blue/azure III or with periodic acid Schiff haematoxylin to show mucus in goblet cells.

\section{IMMUNOHISTOCHEMISTRY}

Three hours after they had been fixed the intestinal pieces were rinsed overnight in phosphate buffered saline containing $7 \cdot 5 \%$ sucrose. They were then frozen in liquid nitrogen and 6 $\mu \mathrm{m}$ cryostat sections were prepared. The sections were incubated with antibodies against toxin $\mathrm{A}$ at $4^{\circ} \mathrm{C}$ for 12 hours, followed by horseradish peroxidase conjugated antibodies (Swine anti-rabbit immunoglobulin-P: Dakopatt, Denmark) for two hours at room temperature. Bound horseradish peroxidase was visualised with the 3,3-diaminobenzidine reaction. Control sections were incubated without the primary antibodies or with antibodies adsorbed with an excess of toxin $\mathrm{A}$.

\section{Results}

\section{FLUID RESPONSE}

The time course of the small intestinal fluid response to toxin $\mathrm{A}(5 \mu \mathrm{g})$ is shown in Figure 1. Fluid accumulation was evident after one hour, the fluid became viscous after two hours, and haemorrhagic after four hours. Fluid accumulation was maximal six hours after challenge.

The dose response six hours after challenge with toxins $A, B$, and $C$ is shown in Figure 2. A low dose $(0.3 \mu \mathrm{g})$ of toxin $A$ induced significant secretion, while $1 \mu \mathrm{g}$ gave some $90 \%$ of the maximal response (Fig 2 (a)). Fraction $\mathrm{C}$ was about 15 times less active than toxin $\mathrm{A}-10 \mu \mathrm{g}$

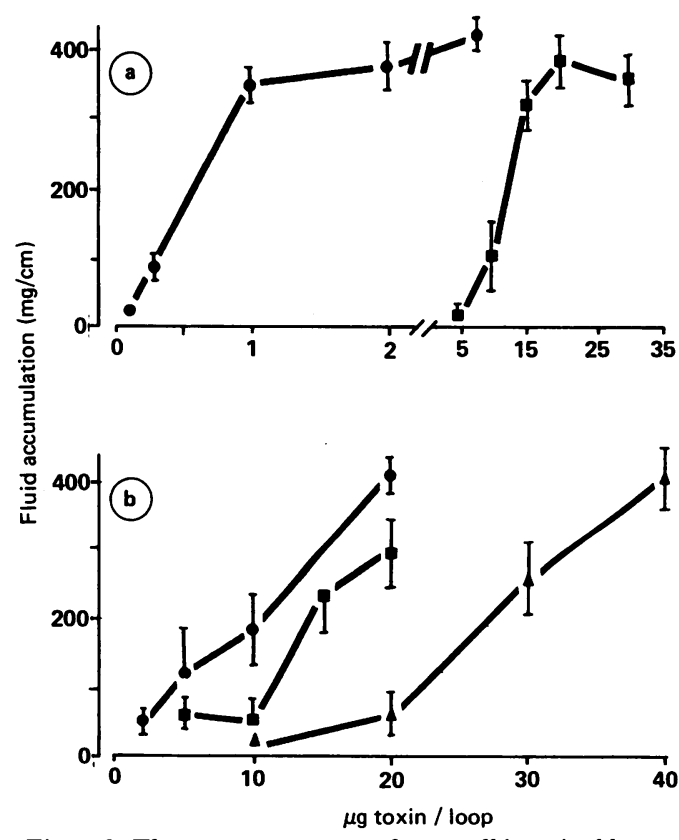

Figure 2: The secretory response of rat small intestinal loops to varying doses of $\mathrm{Cl}$ difficile toxins, six hours after challenge. (a) response to toxin $A(O)$ and toxin $C(\square)$. (b) response to (a) response to toxin $A(O)$ and toxin $C(\square)$. (b) response to
toxin $B$, freshly prepared $(O), 1$ day old ( $)$, and 7 days old $(\Delta)$. Each data point represents the mean of values from six ligated loops and vertical bars the SEM. 
Mean (SEM) fluid secretion in rat colon loops six hours after challenge with Clostridium difficile toxins

\begin{tabular}{|c|c|}
\hline Challenge & Accumulation of fluid ${ }^{\star}(\mathrm{mg} / \mathrm{cm})$ \\
\hline $\begin{array}{l}\text { Toxin A, } 2 \mu \mathrm{g} \\
\text { Toxin B, 40 } \mu \mathrm{g} \\
\text { Fraction C, } 25 \mu \mathrm{g}\end{array}$ & $\begin{array}{r}317(9) \\
<10 \\
57(13)\end{array}$ \\
\hline
\end{tabular}

$\star$ Each value represents the mean (SEM) of four animals.

induced significant secretion and $20 \mu \mathrm{g}$ the maximal response (Fig 2 (a)). The fluid secretion caused by fraction $\mathrm{C}$ was viscous, but there was no bleeding.

Toxin B was tested at different times after it had been produced (Fig 2 (b)). Freshly prepared toxin B had an activity similar to that of fraction $\mathrm{C}$, that is $10 \mu \mathrm{g}$ induced a pronounced response (200 $\mathrm{mg} / \mathrm{cm})$. After one week, however, the activity had decreased significantly, a $30 \mu \mathrm{g}$ dose was required to obtain the same response that
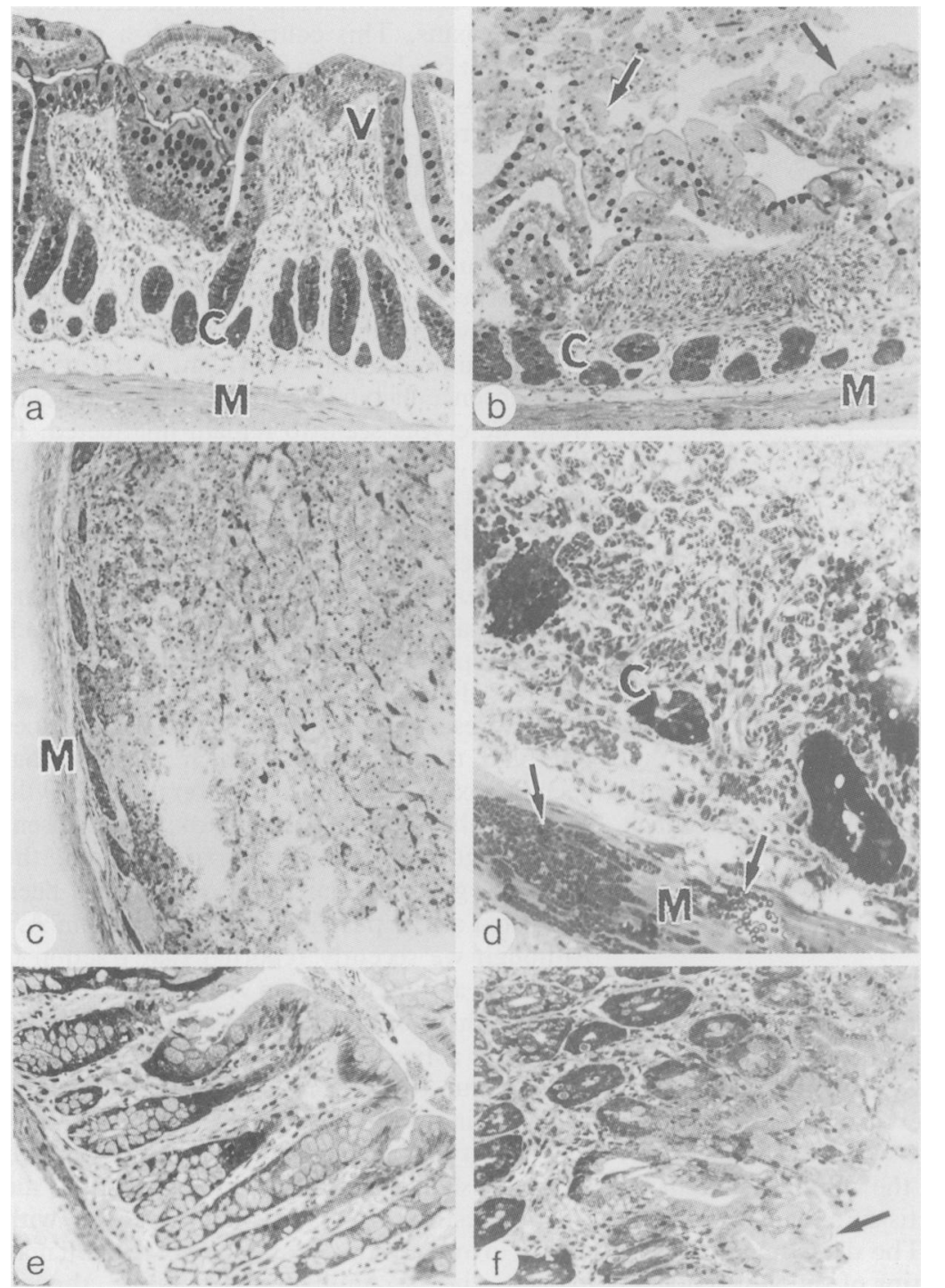

Figure 3: Plastic sections stained with periodic acid Schiff/haematoxylin $(a-c)$, methylene bluelazur III/Basic fuchsin (d-f). V=villus; $C=$ crypt region; $M=$ tunica muscularis. (a) Control loop from small intestine, injected with triethanolamine, NaCl for 6 hours, showing no sign of tissue injury $(\times 100)$. (b) fejunal loop exposed to toxin A, $1 \mu \mathrm{g}$ for 2 hours. Extensive tissue injury is evident. Entire sheets of epithelial cells (arrows) have been sloughed off from the basal membrane $(\times 100)$. (c) Fejunal loop exposed to toxin $A, 1 \mu g$ for six hours. Except for the deeper parts of the crypt region the entire mucosa is damaged $(\times 100) .(d)$ Higher magnification of section similar to that in Figure 3 (c) showing extensive bleeding (arrows) in the submucosa and tunica muscularis 6 hours after injection of toxin $A$. Cells deep in the crypts seem unaffected ( $\times 225)$. (e) Control loop from large intestine injected with triethanolamine, $\mathrm{NaCl}$, showing normal morphology $(\times 175)$. ( $f)$ Loop from the large intestine exposed to toxin $A, 1 \mu g$ for 6 hours. Shedding of cells in the surface epithelium is evident (arrows) $(\times 175)$. had been induced by $10 \mu \mathrm{g}$ of the freshly isolated toxin.

In colon loops, the fluid response to toxin $\mathrm{A}$ was similar to that seen in the small intestine, whereas fraction $\mathrm{C}$ induced a very weak secretion, and toxin B no secretion at all (Table).

HISTOLOGICAL FINDINGS

In the light microscope, loops injected with triethanolamine, $\mathrm{NaCl}$ showed no sign of tissue damage (Fig 3 (a)) whereas extensive damage was already evident two hours after injection of $1 \mu \mathrm{g}$ of toxin A (Fig 3 (b)). Epithelial cell sheets, with the cells still held together by their tight junctions, had detached themselves from the basal membranes of villi. Shed goblet cells seemed to have their normal content of periodic acid Schiff positive material and there was no sign of mucus release. Six hours after challenge, most of the mucosa was necrotic and cellular debris filled the intestinal lumen (Fig 3 (c)). There was also extensive bleeding, both in the submucosal layer and in the tunica muscularis, though epithelial cells deeper in the crypts seemed to be comparatively unaffected (Fig 3 (d)).

In the transverse colon, no damage was induced by triethanolamine, $\mathrm{NaCl}$ injection (Fig 3 (e)). Injection of $1 \mu \mathrm{g}$ toxin $A$ resulted in shedding of cells in the surface epithelium, while no damage was observed in the crypts (Fig 3 (f)).

In jejunal loops injected with toxin $B(20 \mu \mathrm{g}$, one day old), no obvious changes were seen after two hours but after six hours there was slight oedema in some epithelial cells in the tip of villi (Fig 4 (a)). In the colon no morphological effect was observed after administration of this toxin.

In small intestine loops injected with $20 \mu \mathrm{g}$ of fraction $\mathrm{C}$, there was moderate shedding of epithelial cells from the upper part of the villi after two hours (Fig 4 (b)) and extensive damage after six hours affecting most of the villi (Fig 4 (c)). The crypt region seemed mainly unaffected. As in the case of toxin A, exposure to the toxin did not result in any evident release of mucus, and the shed goblet cells were filled with periodic acid Schiff positive material (Fig 4 (d)). Fraction $\mathrm{C}(20 \mu \mathrm{g})$ caused no damage when injected into colon loops.

\section{BINDING OF TOXIN}

Binding of toxin A $(1 \mu \mathrm{g})$ to epithelial cells in the loops was shown by indirect immunohistochemistry using antibodies against toxin A. Exposure of the small intestinal loops to toxin A for one hour resulted in binding of the toxin to enterocytes throughout each villus, whereas there was no binding either to epithelial cells in the crypts (Fig 5 (a)) or to the apical surface of goblet cells (Fig 5 (b)). Immunoreactivity was confined to the microvilli region of the enterocytes, there being none in the cytoplasm. Control sections from loops exposed to toxin A were incubated with preadsorbed immune serum. In these sections no toxin $\mathrm{A}$ immunoreactivity could be detected, thus verifying the specificity of the antiserum used (Fig 5 (c)). In control loops exposed to triethanolamine, $\mathrm{NaCl}$ for 


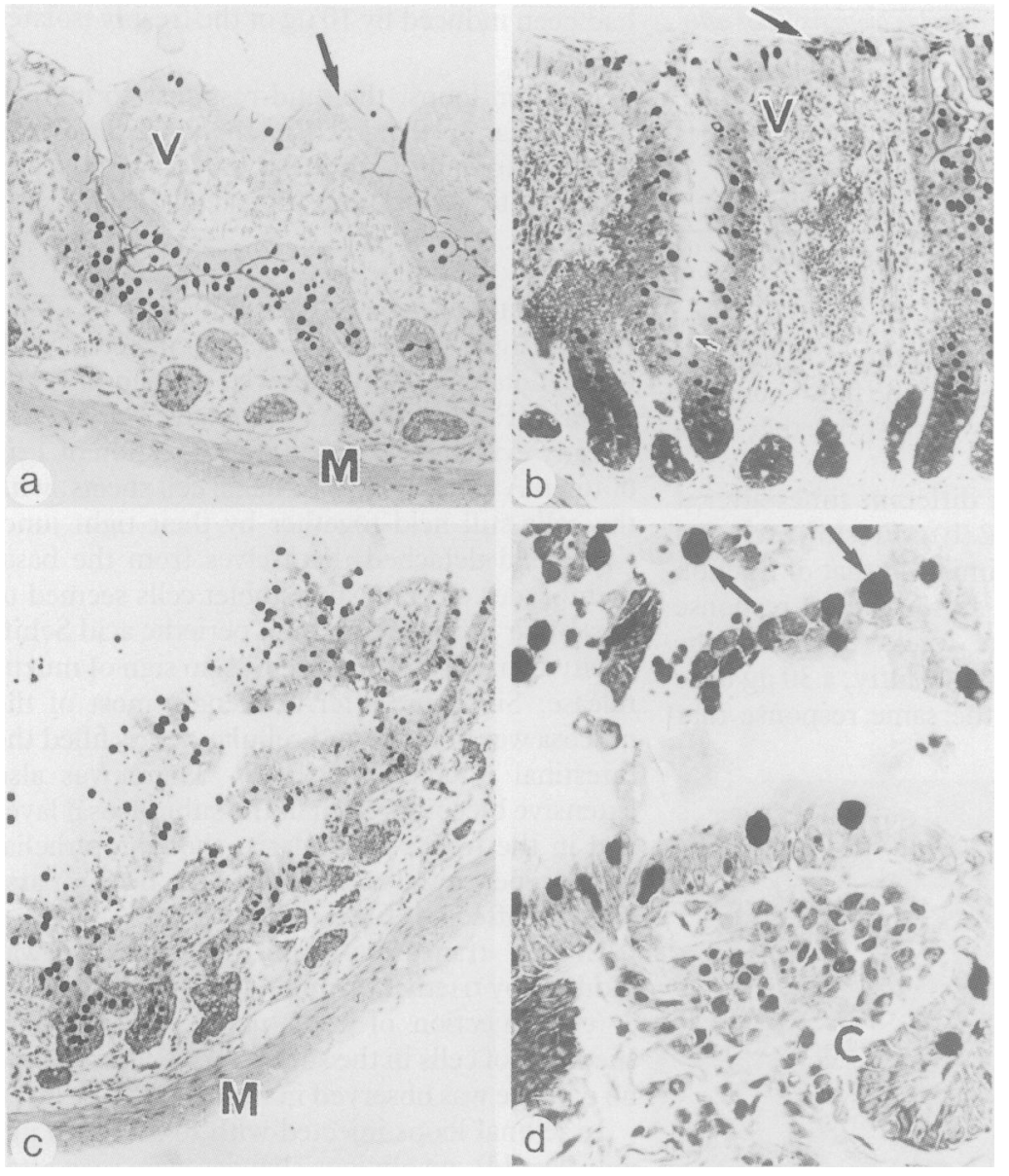

Figure 4: Plastic sections stained with periodic acid Schiff/haematoxylin. (a) fejunal loop exposed to toxin $B, 20 \mu \mathrm{g}$ ( 1 day old) for 6 hours. There is slight oedema in the epithelial cells at the uppermost part of the villi (arrow) $(\times 100)$. (b) Fejunal loop exposed to toxin $C, 20 \mu \mathrm{g}$ for 2 hours. A thin layer of shed epithelial cells can be seen near the uppermost part of the villi (arrow) $(\times 200)$. (c) fejunal loop exposed to toxin $C, 20 \mu \mathrm{g}$ for 6 hours, showing extensive tissue damage, comprising most of the mucosa, but no major bleeding $(\times 100)$. (d) Higher magnification of section similar to that in Figure $4(c)$ showing shed goblet cells with preserved periodic acid Schiff-positive material (arrows) $(\times 100)$.

one hour no immunoreactivity was observed (Fig $5(\mathrm{~d})$ ).

Exposure of colon loops to toxin A (1 $\mu$ g for one hour) resulted in binding of the toxin to the surface epithelium (Fig 5 (e)). As in the small intestine, no binding of toxin A was found either in the crypts or in goblet cells.

\section{Discussion}

The first sign of tissue injury in rat intestinal loops challenged with toxin A was detachment of epithelial cells, held together by their tight junctions at two hours, by which time accumulation of fluid was already evident. Denudation of the villi eliminates the cells which filter water and electrolytes and regulate the complex pressures exerted by the interstitial tissue and blood vessels of the lamina propria. ${ }^{17}$ The detachment of the epithelial cells from the tips of the villi renders the submucosa, including the capillary endothelium, unprotected from bacterial toxic products normally present in the lumen. Furthermore, the osmotic pressure in the loop lumen continuously increases as a result of cellular debris. Thus, several different mechanisms interact in producing fluid accumulation in the ligated loop after denudation of the villi. Injury to the rat intestinal wall by toxin A progressed steadily and after six hours extensive necrosis of the mucosa was observed, including pronounced bleeding in the submucosa and tunica muscularis, though the deeper part of the crypts seemed unaffected. Toxin A also causes extensive necrosis of the intestinal wall, both in the caecum of hamsters ${ }^{18}$ and in the small intestine of rabbits, ${ }^{9}$ though there is also a pronounced inflammatory reaction in these animals. ${ }^{14}$ In the present study in rats, however, no inflammatory reaction was observed. Thus, the epithelial damage seems to be the primary effect, whereas the mediators of the inflammatory reaction probably enhance both the fluid secretion and the tissue damage. ${ }^{19}$

We found that the minimal dose of toxin $\mathrm{A}$ necessary to elicit a maximal fluid response in rat small intestinal loops was five to 10 times lower than that reported for intestinal loops in rabbits. ${ }^{8}$ Considering the potency and morphological effects of toxin $\mathrm{A}$, the rat seems to be a suitable species in which to study the action of $\mathrm{Cl}$ difficile toxins. This contrasts with a previous report that rats had been found to respond poorly to toxin $\mathrm{A},{ }^{20}$ although in that study toxin $\mathrm{A}$ was administered orally and fluid secretion was measured as visible diarrhoea.

The low sensitivity of the crypts to the action of toxin $\mathrm{A}$ is a feature common to all animal models studied, ${ }^{918}$ and has also been observed in biopsy specimens from humans." The present work showed binding of toxin A to be limited to the villi, and no toxin was evident in the crypts. This absence of binding may explain why cells from the crypts seem to remain unaffected. In the colon, too, there was a relation between binding of toxin $\mathrm{A}$ and tissue damage; only those parts of the mucosa which showed binding of toxin A were damaged. Toxin A may be blocked from diffusing into the crypts or it may bind preferentially to mature enterocytes, which would explain why the intestine of infants is unaffected by $\mathrm{Cl}$ difficile toxins. ${ }^{22} 23$

The present results showed that toxin A does not bind to goblet cells, which suggests that specific toxin receptors present on the microvilli region of the differentiated enterocyte are absent from the goblet cell. A glycolipid containing the sequence gal $\alpha 1-3$ gal $\beta 1-4$ glcNac, has been suggested as the putative receptor for toxin A..$^{2+}$ Although we recently reported that fraction $\mathrm{C}$ was more active than toxin $\mathrm{A}$ in an in vitro cell test, " in the present study it was found to be 15 times less active in the gut than toxin A. This may be due to the sensitivity of fraction $\mathrm{C}$ to proteases in the gut - these enzymes do not affect the activity of toxin A." Fraction C caused extensive shedding of cells in the mucosa of the small intestine and, as discussed above with regard to toxin $\mathrm{A}$, this denudation of the villi may explain the accumulation of fluid, though fraction $C$ caused less tissue damage than did toxin $\mathrm{A}$.

In contrast to previous reports, ${ }^{689}$ we found that toxin B does induce accumulation of fluid. The enterotoxic activity was highly unstable, however, which may explain previous failures to discover it. Histology showed that toxin B induced moderate oedema without destruction of the mucosal epithelium, changes which are 


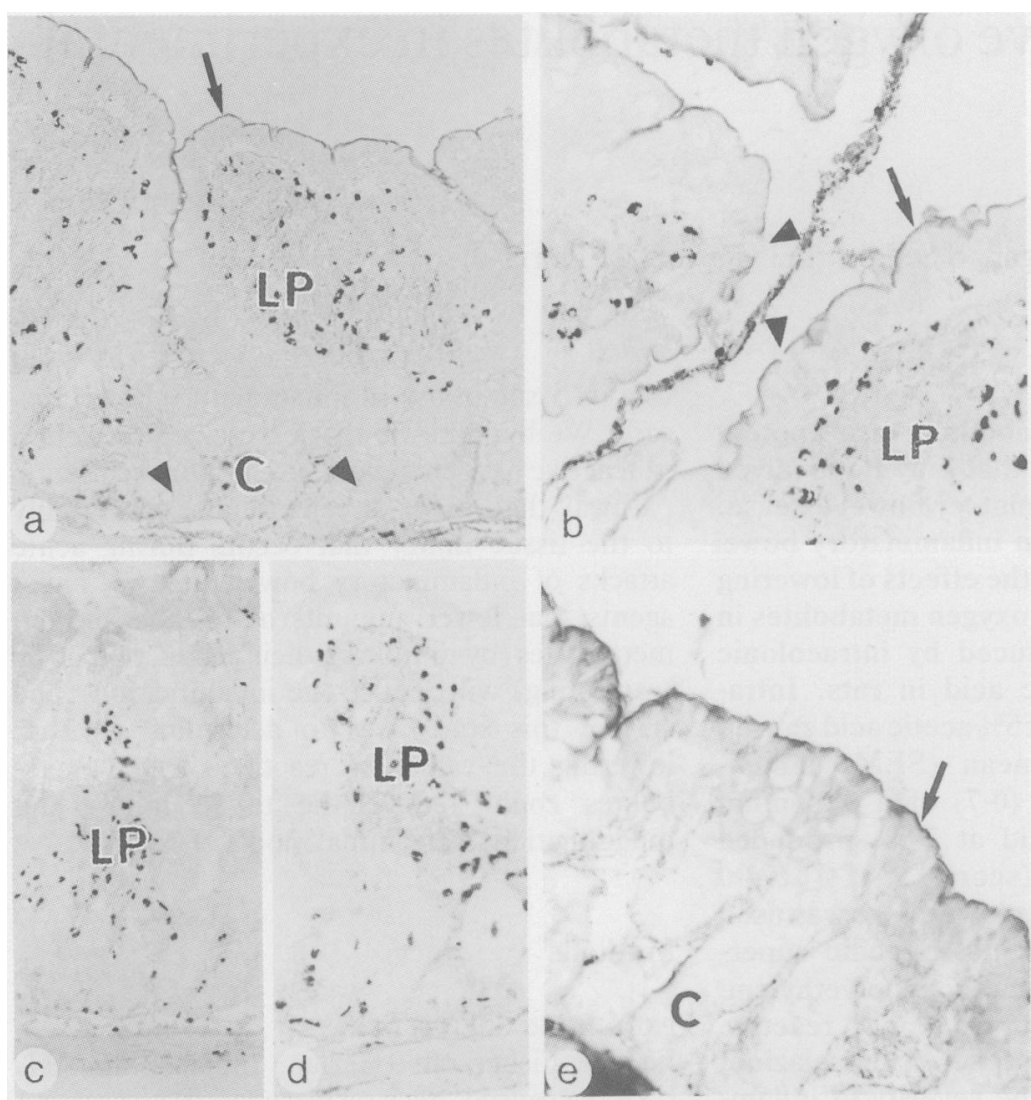

Figure 5: Cryostat sections processed to demonstrate toxin A immunoreactivity, using a $H R P$-conjugated secondary antibody. Leucocytes in the lamina propria $(L P)$ show non-specific staining. $V=$ villus; $C=$ crypt region; $M=$ tunica muscularis. (a) Loop exposed to toxin $A, I \mu g$ for 1 hour, showing toxin $A$ binding on epithelial cells throughout the villi (arrow), but no binding in the crypts (arrow heads) $(\times 120)$. (b) Higher magnification of a section similar to that in Figure 5 (a) showing binding of toxin $A$ in the microvilli region of the enterocytes (arrows). Goblet cells show no binding of toxin A (arrow heads) $(\times 300)$. (c) Fejunal loop exposed to toxin A for 1 hour, incubated with pre-adsorbed immune serum. No specific immunoreactivity is to be seen $(\times 100)$. (d) Loop injected with TES for 1 hour. The section has been incubated with antitoxin $A$ antibodies. No specific immunoreactivity is to be seen $(\times 100)$. (e) Loop from large intestine exposed to toxin $A, 1 \mu \mathrm{g}$ for 1 hour, showing binding of toxin $A$ in the upper part of cells of the surface epithelium (arrow) $(\times 200)$. the result of the dominant expression of one of the toxins produced by this micro-organism $(B$, C or A, or both, respectively).

Financial support was obtained from The Swedish Medical Research Council (grant no 07481), The Medical Faculty of Gothenburg University and The Swedish Council for Forestry and Agricultural Research (grant no 576/86).

1 Bartlett JG. Antibiotic-associated pseudomembranous colitis. Rev Infect Dis 1979; 1: 530-9.

2 Falsen E, Kaijser B, Nehls L, Nvgren B, Svedhem A. Clostridium difficile in relation to enteric bacterial pathogens. F Clin Microbiol 1980; 12: 297-300.

3 Gerding DN, Olson MM, Peterson LR, Teaslev DG, Gedhard RL, Schwarts ML, Lee JT. Clostridium difficile-associated diarrhea and colitis in adults. Arch Intern Med 1986; 146:

4 Abrams GD, Allo M, Rifkin GD, Fekety R, Silva J. Mucosal damage mediated by clostridial toxin in experimental clindamycin-associated colitis. Gut 1980; 21: 493-9.

5 Price AB, Larson HE, Crow J. Morphology of experimental antibiotic-associated enterocolitis in the hamster: a model for human pseudomembranous colitis and antibioticassociated diarrhea. Gut 1979; 20: 467-75

6 Taylor NS, Thorne GM, Bartlett JG. Comparison of two toxins produced by Clostridium difficile. Infect Immun 1981; 34: $1036-43$.

7 Triadafilopoulos G, Pothoulakis C, O'Brien MJ, LaMont JT Differential effects of Clostridium difficile toxins $A$ and $B$ on rabbit ileum. Gastroenterologv 1987; 93: 273-9.

8 Lima AAM, Lyerly DM, Wilkins TD, Innes DJ, Guerrant RJ. Effects of Clostridium difficile toxins $A$ and $B$ in rabbit small and large intestine in vivo and on cultured cells in vitro. Infect Immun 1988; 56: 582-8.

9 Mitchell TJ, Ketley JM, Haslam SC, et al. Effect of toxin A and $B$ of Clostridium difficile on rabbit ileum and colon. Gut 1986; $27: 78-85$

10 Sullivan NM, Pellet S, Wilkins TD. Purification and characterization of toxins A and B of Clostridium difficile. Infect Immun 1982; 35: 1032-40.

11 Torres JF, Lönnroth I. Production, purification and characterization of Clostridium difficile toxic proteins different from toxin A and from toxin B. Biochim Biophys Acta 1989; 998: 151-7.

12 Banno Y, Koboyashi T, Kono H, Watanabe K, Ueno K, Nozawa Y. Biochemical characterization and biological actions of two toxins (D-1 and D-2) from Clostridium difficile. Rev Infect Dis 1984; 6: S11-20.

13 Giuliano M, Piemonte F, Gianfrilli PM. Production of an enterotoxin different from toxin A by Clostridium difficile. FEMS Microbiol Lett 1988; 50: 191-4.

14 Torres JF, Lönnroth I. Purification and characterisation of two forms of toxin $B$ produced by Clostridium difficile. FEBS Letters 1988; 233:2: 417-420.

15 Steinbuch $M$, Audren R. The isolation of $\mathrm{IgG}$ from mammalian sera with the aid of caprylic acid. Arch Biochem malian sera with the aid

16 Lange S. A rat model for an in vivo assay of enterotoxic diarrhea. FEMS Microbiol Lett 1982; 15: 239-42.

17 Menzies IS. Transmucosal passage of inert molecules in health and disease. In: Skadhauge E, Heintze K, eds. Intestinal absorption and secretion. Falk Symposium 36. Lancaster: MTP Press Limited, 1984: 527-43.

similar to those induced by cholera toxin and Escherichia coli LT. ${ }^{25}$ Because of the instability of its enterotoxic action, only fresh preparations of toxin B can be used to study the possible mechanisms, such as stimulation of cyclic adenosine monophosphate or cyclic guanosine monophosphate synthesis in the epithelial cells.

The colon was appreciably less sensitive to the action of these toxins, a finding which is in agreement with those of previous studies. ${ }^{89}$ The secretory effect of toxin B seems to be limited to the small intestine, whereas toxin A was the only toxin showing noticeable secretion and tissue damage in the colon.

The broad spectrum of intestinal disorders associated with $\mathrm{Cl}$ difficile (watery diarrhoea, colitis, and pseudomembranous colitis) may be

Libby JM, Jortner BS, Wilkins TD. Effects of the two toxins of Clostridium in antibiotic-as

19 Mush MW, Miller RJ, Field M, Siegel MI Stimulation of colonic secretion by lipoxygenase metabolites of arachidonic acid. Science 1982; 217: 1255-6.

20 Lyerly DM, Saum KE, MacDonald DK, Wilkins TD. Effects of Clostridium difficile toxins given intragastrically to animals. Infect Immun 1985; 47: 349-52.

21 Price AB, Davies DR. Pseudomembranous colitis. $f$ Clin Pathol 1977; 30: 1-12.

22 Donta ST, Meyers MG. Clostridium difficile toxin in asymptomatic neonates. F Pediatr 1982; 100: $431-4$

23 Iaconis JP, Rolfe RD. Clostridium difficile-associated ileocecitis in clindamycin-treated infant hamsters. Curr Microbiol 1986; 13: 327-32.

24 Krivan HC, Clark GF, Smith DF, Wilkins TD. Cell surface binding site for Clostridium difficile enterotoxin: evidence for a glycoconjugate containing the sequence Galal-3Gal $31-4 \mathrm{GlcN}$ ac. Infect Immun 1986; 53:573-81.

25 Richard KL, Douglas SD. Pathophysiological effects of Vibrio cholerae and enterotoxigenic Escherichia coli and their exotoxins on eucaryotic cells. Microbiol Rev 1978; 42 592-613. 